\title{
Standard Dual Chamber Pacing with Intentional Ventricular Fusion Improving Cardiac Function (Functional CRT) in the Setting of RBBB
}

\author{
Tracy Finegan, NP ${ }^{1}$, Paul A. Levine, MD²*, Mahmoud I. Traina, MD³ , Robin Y. Wachsner, MD ${ }^{4}$ \\ ${ }^{1}$ Heart Failure Clinic, Department of Cardiology, Olive View UCLA Medical Center, Sylmar, California, USA \\ ${ }^{2}$ Device Clinic, Department of Cardiology, Olive View UCLA Medical Center, Sylmar, California, USA \\ ${ }^{3}$ Cardiac Catheterization Laboratory, Department of Cardiology, Olive View UCLA Medical Center, Sylmar, California, USA \\ ${ }^{4}$ Department of Cardiology, Cardiology Olive View UCLA Medical Center, Sylmar, California, USA
}

\begin{abstract}
In a patient with chronic right bundle branch block who requires permanent pacing for the management of sinus node dysfunction, the impact of varying degrees of intentional fusion with a ventricular lead positioned in the right ventricular apex was evaluated with noninvasive Doppler echocardiography. Intentional fusion was shown to improve cardiac function.

Copyright $\odot 2015$ Science International Corp.
\end{abstract}

\section{Key Words}

Fusion - Right bundle branch block • Cardiac resynchronization therapy • Sinus node dysfunction

\section{Introduction}

Cardiac resynchronization therapy (CRT) has been shown to improve left ventricular function and heart failure symptoms [1-3] but only in patients with complete left bundle branch block. Resynchronization therapy does not appear to benefit patients with right bundle branch block (RBBB) and in fact may be harmful [2]. Careful programming of the paced and sensed AV delay, intentional fusion can result in narrowing of the paced QRS complex when a lead is placed in the
RV in the presence of RBBB similar to that originally reported by de Teresa [4] and colleagues in a series of four patients with LBBB and epicardial leads. Detailed Doppler-echocardiographic measurements were obtained at a multiplicity of AV delays to assess any acute hemodynamic benefit in a single patient with sinus node dysfunction, complete RBBB, and left ventricular dysfunction.

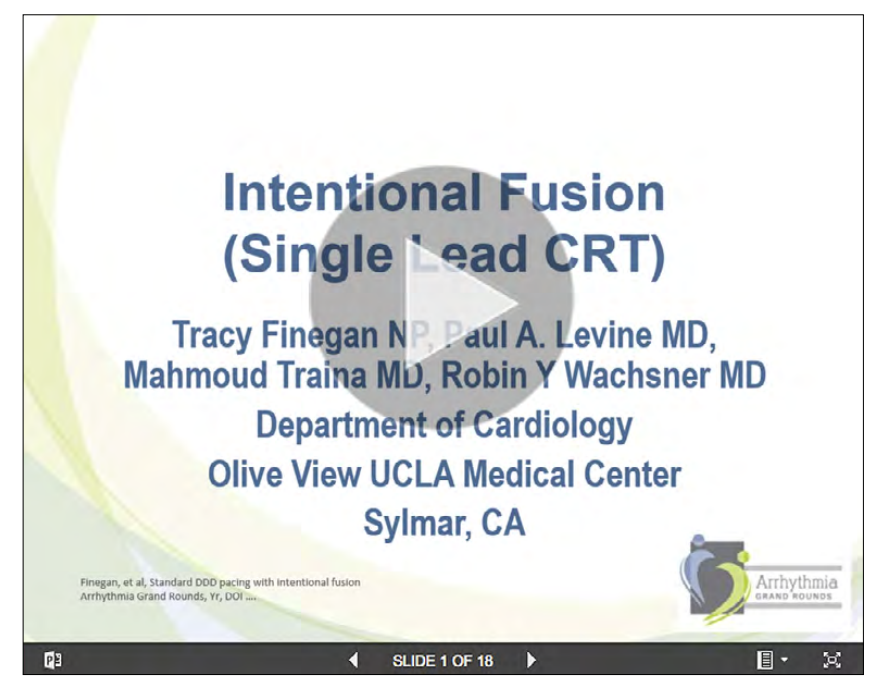

Slideshow. Click on the presentation above to open a new browser window to view the slideshow. Direct link to presentation: http://tiny.cc/agr-00004-15-a. (c) 2015 Arrhythmia Grand Rounds Published by Science International Corp. ISSN 2326-4012

Accessible online at: http://arrhythmiagr.com/
* Corresponding Author:

Paul A. Levine, MD

25876 The Old Road, PMB 14, Stevenson Ranch, California 91381, USA

Tel.: +1 661565 5589, Fax: +1 661254 4702, E-Mail: paul91321@gmail.com 


\section{Case Presentation}

Mr. G is a 61-year-old male with a history of ischemic cardiomyopathy with an ejection fraction of less than $20 \%$. He had a single chamber implanted cardioverter defibrillator (ICD) placed in October 2008 for secondary prevention of ventricular tachycardia (VT). He had multiple episodes of VT with ICD discharge in the first 3 months of the device. The frequency of the tachyarrhythmias was eventually controlled with amiodarone. While up-titrating his beta blocker dose for optimal heart failure therapy, he developed symptomatic bradycardia and pacemaker syndrome associated with VVI pacing. The beta blocker dose was reduced and the amiodarone was held resulting in a recurrence of VT requiring that the amiodarone be restarted along with a desire to resume beta blockade therapy. He was upgraded to a dual chamber ICD for a presumptive diagnosis of sinus node dysfunction due to either his required pharmacologic therapy, progression of intrinsic conduction system disease or a combination of the two with the addition of an atrial lead at the time of pulse generator replacement for battery depletion (September 2010).

Past medical history includes coronary artery disease with an anterior myocardial infarction in September 2008, left ventricular aneurysm, diabetes, and chronic kidney disease. Medications included benazepril, carvedilol, amiodarone, simvastatin, fish oil, warfarin, aspirin, and prn nitroglycerin.

Mr. $G$ was seen for device interrogation in March 2012. At that time, it was noted that there was AV pacing almost $100 \%$ of the time. His paced QRS complex was $248 \mathrm{~ms}$ at a programmed AV delay of $150 \mathrm{~ms}$. Detection of the native QRS complex occurred very late in the complex. At the longest allowed AV delay, the device still delivered a ventricular output but resulting in a pseudofusion beat as there was no change in the morphology of the QRS complex compared to that seen when pacing in the AAI mode and that had a duration of $200 \mathrm{~ms}$. In that we were unable to eliminate pacing, and despite the published literature suggesting that standard CRT was ineffective in most patients with RBBB, a formal study was undertaken to determine if intentional fusion could improve cardiac function, since stimulation would occur via the lead placed in the RV and intrinsic conduction to the right ventricle occurred late in the QRS complex.
Table 1. Measurements made during Doppler-Echocardiography.

\begin{tabular}{|c|c|c|c|c|c|c|}
\hline $\begin{array}{l}\text { AV } \\
\text { delay } \\
\text { (ms) }\end{array}$ & $\begin{array}{l}\text { QRSd } \\
\text { (ms) }\end{array}$ & $\begin{array}{l}\text { Peak } \\
\text { velocity } \\
(\mathrm{m} / \mathrm{s})\end{array}$ & $\begin{array}{l}\mathrm{VTI} \\
(\mathrm{cm} / \mathrm{s})\end{array}$ & $\begin{array}{l}\text { SV } \\
(\mathrm{mL})\end{array}$ & $\begin{array}{l}\text { HR } \\
\text { (bpm) }\end{array}$ & $\begin{array}{l}\mathrm{CO} \\
(\mathrm{L} / \mathrm{min})\end{array}$ \\
\hline 150 & \multirow[t]{3}{*}{248} & 0.594 & 15 & 51.9 & 60 & 3.11 \\
\hline 200 & & 0.594 & 15 & 51.6 & 60 & 3.10 \\
\hline 250 & & 0.698 & 20 & 69.2 & 60 & 4.15 \\
\hline 300 & \multirow[t]{2}{*}{168} & 0.898 & 23 & 79.6 & 60 & 4.76 \\
\hline 300 & & 0.866 & 21 & 72.7 & 60 & 4.36 \\
\hline AAl & 200 & 0.770 & 19 & 65.7 & 60 & 3.94 \\
\hline $\begin{array}{l}\mathrm{VTI}=\mathrm{vel} \\
\mathrm{CO}=\mathrm{car}\end{array}$ & $\begin{array}{l}\text { time } \\
\text { output. }\end{array}$ & integral; & SV & & & eart \\
\hline
\end{tabular}

\section{Results}

To evaluate the hemodynamic benefit of fusion pacing in this patient, Doppler-echocardiography was utilized to measure the peak velocity of the blood in $\mathrm{m} / \mathrm{s}$ (meters per second) through the left ventricular outflow tract (LVOT) at varying AV intervals. A velocity time integral (VTI) was measured for each AV interval by Doppler and the cross-sectional area (CSA) was calculated at $3.46 \mathrm{~cm}^{2}$ using the measured LVOT diameter of $2.1 \mathrm{~cm}$ at the base of the aorta $\left[C S A\left(\mathrm{~cm}^{2}\right)=3.14(\mathrm{D} / 2)^{2}\right]$. For each AV interval tested, a stroke volume (SV) was calculated utilizing the formula SV=CSA $\times$ VTI. As the patient has sick sinus syndrome, the programmed base rate set at 60 beats per minute (bpm) resulted in a stable rate and each cardiac output (CO) was calculated using a heart rate of $60 \mathrm{bpm}$ multiplied by the SV. The data is displayed in Table 1.

Five different measurements were made at four different programmed AV delays and one measurement at the patient's own intrinsic AV interval while pacing AAI. It was determined that the AV interval with the highest peak velocity was $300 \mathrm{~ms}$. This setting yielded the highest cardiac output of $4.76 \mathrm{~L} / \mathrm{min}$. The resultant QRS duration had narrowed from an intrinsic duration of $200 \mathrm{~ms}$ to $168 \mathrm{~ms}$ with intentional 
AV delay: $150 \mathrm{~ms}$

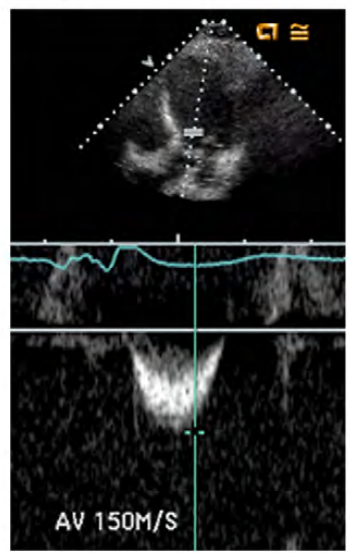

CO

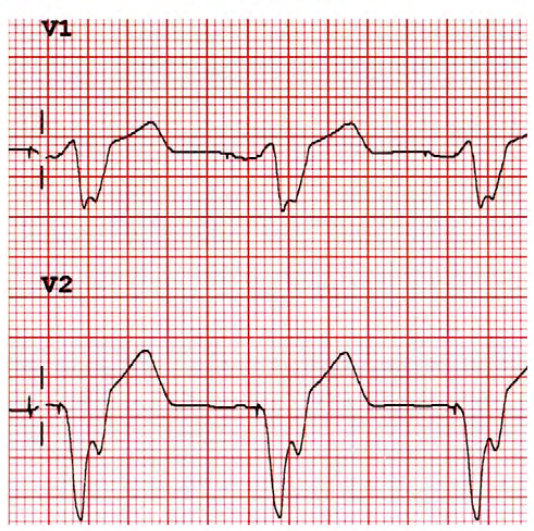

$300 \mathrm{~ms}$

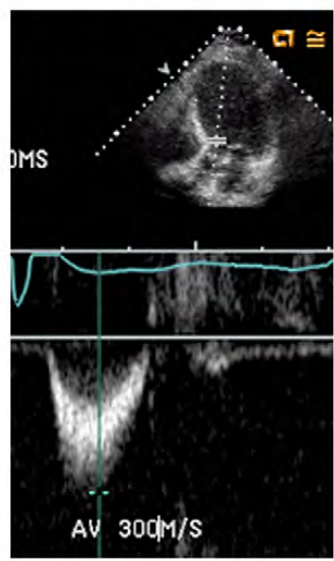

4.76 L/min

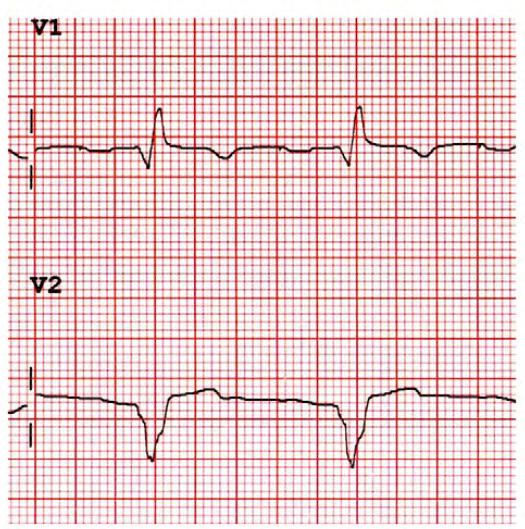

AAl

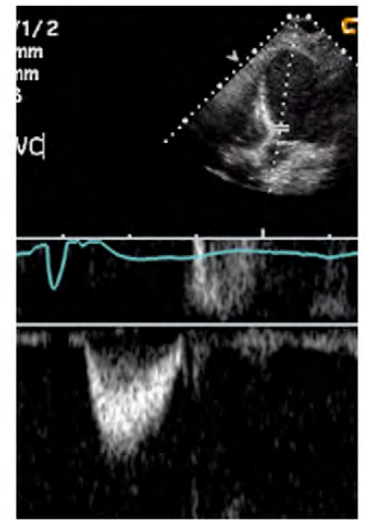

$3.94 \mathrm{~L} / \mathrm{min}$

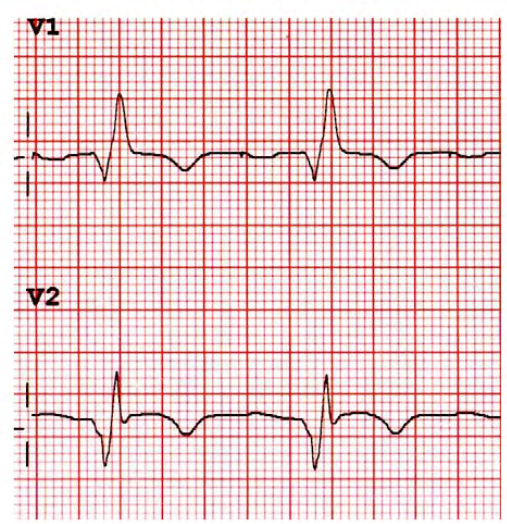

Figure 1. This is a composite illustration showing the Doppler signal in the LV outflow tract on the top and the simultaneously recorded ECG displaying leads V1 and V2 below it. The ECG recording speed was $25 \mathrm{~mm} / \mathrm{s}$. The calculations are shown in Table 1.

fusion. Selected panels for AV delays of 150 and 300 ms along with AAI pacing showing the Doppler display and the simultaneously recorded QRS complex are shown in Figure 1.

\section{Discussion}

The intrinsic QRS duration is $200 \mathrm{~ms}$ and, due to fusion, the paced QRS complex was $168 \mathrm{~ms}$ at a programmed AV delay of 300 ms. The pacing system appears to be acting as a CRT device, causing narrowing of his RBBB and a consistently measureable improvement in cardiac output based on this noninvasive method.

In the presence of first degree AV block, program- ming of the AV delay to cause ventricular fusion may lead to improved cardiac function by effectively narrowing if not totally normalizing the ventricular activation sequence in patients with an indication for pacing. Although this is not biventricular pacing, it is functionally equivalent to multisite pacing. In this patient, the QRS was significantly narrowed, and we achieved the higher cardiac output when utilizing ventricular fusion over that achieved with intrinsic conduction.

There are limitations to this study. First, these measurements were obtained with the patient at rest in a supine position and not during exercise. Therefore, the AV delay obtained may only be an approximation of the optimal AV delay in other physiologic states 
(upright, walking, etc.). Secondly, this study was done at one point in time. Clinically the patient is doing well but formal follow-up studies have not been performed to determine if the demonstrated benefit remains intact.

In conclusion, cardiac resynchronization may effectively be achieved with a dual chamber device by adjusting the AV delay to narrow the QRS duration and improve the ventricular activation sequence. Whether the improvement in cardiac output is due to the alteration in the ventricular activation sequence or an "optimal" AV delay or a combination of the two cannot be determined from this study.

\section{References}

1. Bristow MR, Saxon LA, Boehmer J, Krueger $\mathrm{S}$, Kass DA, De Marco T, et al. Cardiac resynchronization therapy with or without an implantable defibrillator in advanced chronic heart failure. New Engl J Med. 2004;350:2140-2150. DOI: 10.1056/NEJMoa032423

2. Zareba W, Klein H, Cygankiewicz I, Hall WJ, McNitt $S$, Brown M, et al. Effectiveness of cardiac resynchronization therapy by QRS morphology in the multicenter automatic defibrillator implantation trial-cardiac resynchronization therapy. Circulation. 2011;123:1061-1072. DOI: 10.1161/CIRCULATIONAHA. 110.960898

\section{Conflict of Interest}

While TF has no conflicts of interest relevant to this publication, MT and RYW both lecture for a number of pharmaceutical companies and PAL owns equity interest in two device manufacturers.

\section{Comment on this Article or Ask a Question}

3. Linde C, Abraham WT, Gold MR, St. John Sutton M, Ghio S, Daubert C. Randomized trial of cardiac resynchronization in mildly symptomatic heart failure patients and in asymptomatic patients with left ventricular dysfunction and previous heart failure symptoms. J Am Coll Cardiol. 2008;52:1834-1843. DOI: 10.1016/j. jacc.2008.08.027

4. de Teresa E, Chamorro JL, Pulpan LA, Ruiz C, Bailon R, Alzveta J, et al. An even more physiologic pacing - changing the sequence of ventricular activation. In: Steinbach K, Glogar D, Laszkovics A. Cardiac Pacing, Proceedings of the VIlth World
Symposium on Cardiac Pacing, Steinkopff Verlag, Darmstadt Germany; 1983, p. 395400.

Cite this article as: Finegan $\mathrm{T}$, Levine PA, Traina MI, Wachsner RY. Standard Dual Chamber Pacing With Intentional Ventricular Fusion Improving Cardiac Function (Functional CRT) in the Setting of RBBB. Arrhythmia Grand Rounds 2015;1(2):63-66. DOI: http://dx.doi. org/10.12945/j.agr.2015.004-15 